\title{
Análise do nível de disclosure quanto à aplicação do Pronunciamento Técnico CPC27: um estudo aplicado nas empresas de capital aberto do Brasil, Argentina e Chile.
}

\author{
Fabrício de Macedo \\ Centro Universitário Católica de Santa Catarina \\ fabricio.macedo@catolicasc.org.br \\ Lucas Anderson da Silva \\ Centro Universitário Católica de Santa Catarina \\ lucas1995.silva@catolicasc.org.br
}

\section{Resumo}

As normas internacionais de contabilidade proporcionaram a harmonização e padronização dos procedimentos e das normas contábeis aplicadas nas organizações. Visando atender a necessidade do Brasil em se adequar aos padrões internacionais, foi criado o Comitê de Pronunciamentos Contábeis - CPC através da resolução CFC $n^{0} 1.055 / 05$, que possui o objetivo de traduzir as normas emitidas pelo International Accounting Standards Board (IASB). Dentre os pronunciamentos emitidos pelo CPC, se encontra o CPC 27, que expõe sobre os assuntos pertinentes ao ativo imobilizado, e como instrumento deste estudo nele consta o tópico de divulgação. $O$ objetivo do estudo é conhecer o nível de disclosure das empresas brasileiras, argentinas e chilenas de capital aberto em relação ao atendimento dos requisitos de divulgação do pronunciamento técnico CPC 27. A pesquisa é de caráter descritivo, com abordagem qualitativa, e utilização de procedimentos bibliográficos e documentais. De maneia geral, conclui-se que em nenhum dos três países analisados foi possível obter $100 \%$ de aderência em todos os quesitos aplicados. Em relação ao total de quesitos evidenciados, o Chile atingiu o INDCOMB de $83,53 \%$, em 2015, e 82,94\%, em 2016, representando superioridade na evidenciação, conforme comparação com o Brasil, que alcançou 78,75\% para 2015 e 2016, e a Argentina, que auferiu $80,00 \%$ para os mesmos períodos.

Palavras-chave: Disclosure. Ativo Imobilizado. CPC 27.
ISSN: $1984-6266$

Recebimento:

$02 / 04 / 2018$

Aprovação:

22/04/2019

Editor responsável pela aprovação do artigo:

Dr. Flaviano Costa

Editor responsável pela edição do artigo:

Dr. Flaviano Costa

Avaliado pelo sistema:

Double Blind Review

A reprodução dos artigos, total ou parcial, pode ser feita desde que citada a fonte.

PROGRAMA DE PÓS-GRADUAÇ̃̃O EM CONTABILIDADE uFrR MESTRADO E DOUTORADO

DOI:

http://dx.doi.org/10.5380/rc\&c.v10i2.58689 


\title{
ANALYSIS OF LEVEL OF DISCLOSURE REGARDING THE APPLICATION OF TECHNICAL PRONOUNCEMENT CPC 27: A STUDY APPLIED TO CAPITAL OPEN COMPANIES OF BRAZIL, ARGENTINA AND CHILE
}

\begin{abstract}
International accounting standards have provided harmonization and standardization of procedures and accounting standards applied in organizations. In order to meet Brazil's need to comply with international standards, the Accounting Pronouncements Committee (CPC) was established through CFC Resolution No. $1,055 / 05$, which aims to translate the standards issued by the International Accounting Standards Board (IASB). Among the pronouncements issued by the CPC is CPC 27, which sets out the issues related to property, plant and equipment, and as an instrument of this study the topic of disclosure is included in it. The objective of the study is to know the level of disclosure of Brazilian, Argentine and Chilean publicly traded companies in relation to meeting the disclosure requirements of technical pronouncement CPC 27. The research is descriptive, with a qualitative approach, and the use of bibliographic procedures and documentaries. In general, it was concluded that in none of the three countries analyzed was it possible to obtain $100 \%$ adherence in all the applied questions. Regarding the total number of items highlighted, Chile reached INDCOMB of $83.53 \%$ in 2015 and $82.94 \%$ in 2016, representing superiority in the disclosure, as compared with Brazil, which reached $78.75 \%$ by 2015 and 2016, and Argentina, which received $80.00 \%$ for the same periods.
\end{abstract}

Keywords: Disclosure. Fixed Assets. CPC 27.

\section{Introdução}

A contabilidade sofreu diversas modificações ao longo dos anos com o intuito de melhorar sua aplicação e evidenciação, porém seu objetivo principal de auxiliar na tomada de decisões sempre foi conservado. Conforme Marion (2009), a contabilidade é o instrumento que visa fornecer o máximo de informações confiáveis e fidedignas para auxiliar na tomada de decisões dos gestores e terceiros interessados.

No Brasil, o cenário contábil teve sua modificação mais relevante através da necessidade de adequar suas normas contábeis aos padrões internacionais. O Comitê de Pronunciamentos Contábeis - CPC foi 0 representante desta convergência no Brasil, criando os pronunciamentos técnicos sobre determinada conta ou grupo de conta, como o CPC 27, que expõe o tratamento contábil para o Ativo Imobilizado, que será material de estudo para a pesquisa. (CPC, 2009).

Dessa forma, conforme exposto no pronunciamento técnico CPC 27 (2009), seu objetivo é esclarecer e fornecer informações sobre 0 ativo imobilizado de determinada organização, com a finalidade de complementar os números trazidos nas demonstrações contábeis que muitas vezes não esclarecem a real situação do imobilizado.

É através da necessidade de transparência e do conjunto de informações que a pesquisa busca responder a seguinte questão: Qual é o nível de disclosure das empresas brasileiras, argentinas e chilenas de capital aberto em relação ao atendimento dos requisitos de divulgação do pronunciamento técnico CPC 27 Ativo Imobilizado?

Diante do exposto, o objetivo geral da pesquisa é conhecer o nível de disclosure das empresas brasileiras, argentinas e chilenas de capital aberto em relação ao atendimento dos requisitos de divulgação do pronunciamento técnico CPC 27 - Ativo Imobilizado.

Com o intuito de complementar e ampliar o objetivo geral da pesquisa, foram determinados os seguintes objetivos específicos: (a) relatar uma abordagem teórica dos principais conceitos que compõem a pesquisa, 
sendo esses, Comitê de Pronunciamentos Contábeis, ativo imobilizado, disclosure e estudos correlacionados; (b) identificar o nível de disclosure em relação aos quesitos de divulgação do CPC 27; (c) verificar uma comparação entre os períodos e os países estudados; (d) validar qual ou quais empresas possuem maior adesão às normas.

A pesquisa amplia-se com o estudo aplicado em três países e em outro setor de atuação, diferente da análise realizada pelos autores Lemos, Longoni e Lemos (2016), que teve como objeto de avaliação as empresas brasileiras de capital aberto do setor de comércio nos períodos de 2010 a 2013 em relação à aplicação do CPC 27 quanto aos quesitos de divulgação. Esta pesquisa se justifica devido à importância da adoção das práticas contábeis que estão em convergência com os padrões internacionais da contabilidade.

Diante do exposto, é de relevância que as empresas respeitem os quesitos do CPC 27, demonstrando maior transparência e seriedade para os usuários, considerando que 0 ativo imobilizado é um item definitivamente representativo do ativo, podendo impactar de forma relevante os resultados da empresa. Para a continuação do estudo, a pesquisa é ampliada proporcionando a comparação entre três países.

Além do Brasil, foram escolhidos para análise a Argentina e o Chile. A Argentina levando em consideração que faz fronteira com o Brasil, segundo dados do Banco Mundial, representa uma das maiores economias da América Latina, obtendo um crescimento econômico significante na última década. Já o Chile, devido a sua reforma na educação, conforme dados do Banco Mundial, nas últimas décadas apresentou uma redução expressiva da pobreza de sua população, por meio de um crescimento econômico acelerado.

Em relação ao setor estudado, foi escolhido o consumo não-cíclico, pois segundo o Investopedia, mesmo em épocas de crise e recessão essas empresas têm seus resultados menos afetados, por representarem o ramo do alimento, bebida, saúde, etc. $O$ trabalho está dividido em 5 partes, sendo esta a primeira, possibilitando uma prévia do que será estudado. A segunda evidencia sobre o fundamento de forma detalhada, incluindo conceitos sobre CPC, ativo imobilizado e divulgação. Já a terceira, mostra os métodos explorados para o desenvolvimento do estudo. Em seguida, na quarta etapa, é demonstrada a análise dos resultados e, por fim, na última etapa, a conclusão, na qual se pode observar que o objetivo do artigo foi atingido.

\section{Referencial Teórico}

Este capítulo dispõe sobre os temas relacionados ao problema da pesquisa. Inicialmente será apresentado um breve resumo sobre o Comitê de Pronunciamentos Contábeis, destacando sua constituição e finalidade. Após, serão abordadas informações sobre o ativo imobilizado e disclosure. E, para finalizar, serão expostos os estudos correlacionados ao tema proposto.

\subsection{Comitê de Pronunciamentos Contábeis}

O mundo claramente caminha para uma convergência contábil. Mais de 100 países já adotaram e aplicaram o International Financial Reporting Standard (IFRS), padrão contábil que será globalmente aceito na produção e publicação das demonstrações financeiras. Em função disso, o responsável pela publicação das devidas normas será o International Accounting Standards Board (IASB) (Deloitte, 2017).

No Brasil, o CPC teve sua constituição através da resolução CFC no 1.055/05, idealizado a partir da união das seguintes entidades: Associação Brasileira das Companhias Abertas (ABRASCA), Associação dos Analistas e Profissionais de Investimento do Mercado de Capitais (APIMEC NACIONAL), B3, Conselho Federal de Contabilidade (CFC), Instituto dos Auditores Independentes do Brasil (IBRACON) e a Fundação Instituto de Pesquisas Contábeis, Atuariais e Financeiras (FIPECAFI) (Resolução CFC n 1.055, 2005). Este comitê tem a finalidade de executar pronunciamentos, interpretações e orientações com base nas normas internacionais 
emitidas pelo $I A S B$, possuindo assim o objetivo de formular padrões contábeis e desenvolver aceitação e observância mundial. Logo, os órgãos reguladores contábeis brasileiros concordam e aprovam as decisões e os documentos emitidos pelo CPC e os tornam definitivamente obrigatórios. (ludícibus, Kanitz, Martins, 2010).

O CPC, na maioria das situações, deverá apenas traduzir as normas emitidas pelo IASB. Se necessário, poderão ser feitos ajustes com a intenção de exemplificar e definir melhor alguns itens para a aplicabilidade brasileira, mas o fundamento inicial não deverá ser modificado. Em alguns casos extremos, poderá ocorrer uma não convergência, esta deverá ser temporária e sanada quando possível. Inclusive, se 0 CPC concluir que tem condições de emitir uma norma tecnicamente melhor ou verificar que há problemas e imperfeições na emissão feita pelo IASB, poderá informar o órgão internacional para a devida verificação. (Martins; Martins \& Martins, 2007).

Para o contexto brasileiro, a criação do CPC e a harmonização aos padrões internacionais trouxeram pontos positivos para o país, devido ao esforço necessário para a uniformização e centralização das normas contábeis. Este processo de convergência ocorreu pela necessidade de comparar números produzidos pela contabilidade, com a intenção de confrontar um período ao outro de uma mesma empresa ou também comparar uma empresa nacional com uma internacional. (Oliveira \& Lemes, 2012).

\subsection{Ativo Imobilizado}

Os bens do ativo imobilizado geralmente representam uma parcela bem significativa em relação ao valor total do ativo de uma empresa e devem possuir vida útil superior a um ano. Sua utilidade baseia-se principalmente na fabricação de produtos relacionados à atividade da organização e na manutenção da sua parte administrativa. Estes ativos deverão ser registrados no balanço patrimonial pelo custo incorrido em sua aquisição. (Almeida, 2014).

Neste grupo do ativo são classificados os bens e direitos que foram adquiridos em prol da operação da empresa. É a composição dos itens necessários para que a entidade possa desenvolver suas atividades e alcançar o objetivo para o qual foi criada, logo, esses itens devem ser imobilizados. 0 conceito de imobilizar surgiu da ideia de que esses bens não estão disponíveis para revenda e, portanto, devem ficar imóveis na empresa, visto que são utilizados em sua atividade operacional. (Padoveze, 2012).

Desta forma, "entende-se por ativo imobilizado todo o ativo de natureza relativamente permanente, que se utiliza na operação de negócios de uma empresa e que não se destina à venda." (Marion 2009, p. 217). Analisando os conceitos apresentados, é evidente que para o ativo ser considerado um imobilizado, precisará estar em conformidade com as três exigências descritas: possuir natureza permanente, ser utilizado na operação da empresa e não ser destinado à venda.

O Comitê de Pronunciamentos Contábeis, em seu pronunciamento técnico CPC 27 em correlação às normas internacionais de contabilidade IAS 16, expõe, em seu item seis, a definição do ativo imobilizado da seguinte forma:

Ativo imobilizado é o item tangível que: (a) é mantido para uso na produção ou fornecimento de mercadorias ou serviços, para aluguel a outros, ou para fins administrativos; e (b) se espera utilizar por mais de um período. Correspondem aos direitos que tenham por objeto bens corpóreos destinados à manutenção das atividades da entidade ou exercidos com essa finalidade, inclusive os decorrentes de operações que transfiram a ela os benefícios, os riscos e o controle desses bens. (CPC, 2009)

A característica principal de um imobilizado é a de poder ser utilizado nas operações normais da empresa e necessitar que sua vida útil seja mais extensa que o ciclo operacional, sendo assim de longa 
duração. 0 grupo do imobilizado tangível pode compor itens como: terrenos, edifícios, equipamentos, móveis, veículos, entre outros. (ludícibus, 2010).

O conceito do ativo imobilizado se equipara ao conceito de capital, ambos estabelecem limites aos seus itens geradores de fluxos de caixa. Desta maneira, podem-se definir diversas formas de capital, capital físico, capital intelectual, capital humano, entre outros. Neste estudo, trata-se do capital físico (tangível), o qual será determinado como ativo imobilizado. (Eckert, Mecca, Biasio \& Souza, 2012).

\subsection{Disclosure}

A palavra disclosure está diretamente ligada ao ato de divulgar, evidenciar e expor, isto é, tornar pública determinada informação. No contexto corporativo, este termo está relacionado à divulgação de informações sobre determinada empresa, objetivando fornecer transparência aos usuários externos. A evidenciação pode ser voluntária, quando tem a intenção de complementar, ou obrigatória quando é exigida mediante lei. Quanto maior o nível de disclosure, maior será a transparência da organização. (Murcia, Souza, Dill \& Costa Junior, 2010).

Para Gibbins, Richardson e Waterhouse (1990), o termo disclosure seria a divulgação contábil obrigatória ou voluntária, de caráter quantitativo ou qualitativo, produzida pela empresa através dos seus relatórios anuais, com a intenção de auxiliar os usuários externos para a tomada de decisão. Goulart (2003) contribui conceituando o disclosure como a abertura da demonstração financeira de uma empresa por meio da divulgação, assegurando a transparência corporativa para o público e para os usuários interessados participantes do mercado.

A evidenciação (disclosure) está ligada diretamente ao objetivo da contabilidade em fornecer informações relevantes aos vários tipos de usuários. Existem diversos conceitos utilizados para expressar 0 termo evidenciação, é comum a apresentação de três termos diferentes: evidenciação adequada, justa e plena. Embora sejam atribuídos significados distintos para cada um deles, não deve existir diferença efetiva entre os conceitos, pelo fato de que toda informação contábil deve ser, ao mesmo tempo, adequada, justa e plena. Esta afirmação contribui para o sentido real da evidenciação, que é de omitir as informações não relevantes, apresentando apenas itens significativos, possibilitando a correta interpretação das demonstrações contábeis. (ludícibus, 2010).

Embora no Brasil o termo evidenciação esteja diretamente relacionado às notas explicativas, existem várias formas de aplicar a divulgação das demonstrações contábeis, como por exemplo: (a) forma e apresentação das demonstrações contábeis; (b) informação em parênteses; (c) notas explicativas; (d) quadros e demonstrativos suplementares; (e) comentários do auditor e (f) relatório da administração. (ludícibus, 2010).

Para 0 ativo imobilizado, a entidade deve divulgar as práticas adotadas, visando exemplificar e compor as informações que os números não podem fornecer. Esta prática deve ocorrer através das notas explicativas, conforme o tópico de divulgação do CPC 27. Divulgar os métodos utilizados em relação ao imobilizado da empresa proporciona a real visualização da situação do ativo e possibilita uma comparação mediante os aspectos aplicados, demonstrando transparência e confiabilidade. (Lemos, Longoni \& Lemos, 2016).

\subsection{Estudos correlacionados}

Este tópico visa expor os estudos publicados correlacionados ao tema base para a execução desta pesquisa. Para tanto, leva-se em consideração a evidenciação do ativo imobilizado, conforme estabelece 0 CPC 27. Serão apresentados os métodos, objetivos e resultados atingidos por diversos autores acerca do 
assunto proposto. Mediante isso, obteve-se seis análises pertinentes ao tema, sendo essas, publicadas entre os períodos de 2012 a 2016.

Reis e Nogueira (2012) realizaram sua análise com base em 82 empresas, pertencentes ao novo mercado da bolsa de valores de São Paulo, utilizando as demonstrações financeiras referentes ao ano de 2009. O Objetivo da pesquisa visa verificar a adequação das empresas quanto à nova exigência imposta pelo CPC 27 , referindo-se às taxas de depreciação e registro do imobilizado. Os resultados apontam que apenas 13 empresas (16\%) evidenciaram corretamente os quesitos propostos, como também, 28 companhias (34\%) já utilizaram a nova taxa de depreciação estabelecida.

Já Viviani, Beck, Hall e Klann (2014), analisaram 34 empresas pertencentes ao setor de bens industriais listadas na B3, efetivando o estudo com base nas notas explicativas relativas ao período de 2011. 0 objetivo geral do estudo busca verificar o nível de adoção quantos aos requisitos de evidenciação determinados pelo CPC 27. Obteve-se a conclusão de que, de maneira geral, as entidades estão atendendo parcialmente as exigências, porém, as informações básicas são evidenciadas.

Contudo, Silva, Kutianski e Scherer (2014) examinaram a amostra de 33 empresas associadas ao setor bens industriais listadas na B3, elaborando a análise sobre os períodos de 2008 a 2013. Fixou-se o objetivo de avaliar os fatores explicativos do nível de evidenciação do ativo imobilizado, buscando relacionar as variáveis das companhias com o seu desempenho de disclosure. Frente a isso, conclui-se que as variáveis de tamanho, endividamento, CPC e Big Four representam fatores significativos para exemplificar o nível de divulgação. Vale ressaltar também que, nem mesmo as organizações auditadas pelas Big Four possuem $100 \%$ de adequação às exigências.

Por outro lado, Kaveski, Carpes e Klann (2015) averiguaram 106 companhias listadas no segmento do Novo Mercado de Governança Corporativa da B3, auferindo pesquisa sobre as demonstrações contábeis do período de 2011. Os autores possuíram o objetivo de identificar os fatores explicativos quanto ao nível de divulgação dos requisitos do CPC 27. O resultado auferido demonstrou que nenhuma das empresas cumpriu todas as exigências, porém, observou-se uma relação positiva entre 0 valor do imobilizado da companhia e 0 total de disclosure atingido.

Dessa perspectiva, Caliman (2015) desenvolveu uma análise aplicada em cinco empresas pertencentes ao segmento de siderurgia, todas listadas na B3, utilizou-se as notas explicativas dos anos de 2012 e 2013. Nesse sentido, buscou-se analisar o disclosure das companhias mencionadas, visando 0 atendimento às exigências do CPC 27. Constatou-se que nenhuma das entidades analisadas atendeu todos os quesitos mencionados, demonstrando eventual inconformidade com as exigências propostas, fixando a necessidade de melhoria.

Por fim, Lemos, et al (2016) analisaram a amostra de 17 empresas listadas na B3, todas pertencentes ao setor de comércio. Para a execução da pesquisa, consideraram-se as notas explicativas dos períodos de 2010 a 2013. $O$ objetivo do estudo visou mensurar o nível de conformidade das companhias de capital aberto, tendo como base as exigências de divulgação do CPC 27. Conclui-se que as entidades analisadas auferiram o percentual de $76 \%$ quanto à evidenciação do imobilizado.

\section{Procedimentos Metodológicos}

Esta pesquisa se caracteriza como sendo descritiva, devido à classificação em relação ao seu objetivo. Segundo Gil (2008, p.28), "as pesquisas deste tipo tem como objetivo primordial a descrição das características de determinada população ou fenômeno ou o estabelecimento de relações entre variáveis".

Nesse sentido, o presente trabalho buscará descrever o nível de disclosure das empresas brasileiras, argentinas e chilenas de capital aberto em relação ao atendimento dos requisitos de divulgação do pronunciamento técnico CPC 27 - Ativo Imobilizado. 
Quanto à abordagem do problema, a pesquisa é de caráter qualitativo, pois será descritiva, demonstrando o resultado obtido com a análise e mensuração da amostra selecionada em relação ao problema. Os procedimentos desenvolvidos na pesquisa desse artigo dar-se-ão de forma bibliográfica e documental, tendo como fonte as demonstrações contábeis publicadas. (Gil, 2008).

De acordo com Gil (2010), a pesquisa bibliográfica tem como fonte de informação toda a bibliografia já publicada, constituída principalmente por livros e artigos científicos, possibilitando a cobertura de uma quantidade ampla de informações. Já a pesquisa documental, novamente descrita pelo autor, tem o intuito de reelaborar informações recebidas de acordo com os objetivos da pesquisa, utilizando-se de materiais que ainda não receberam tratamento analítico, tais como, documentos oficiais, contratos, carta, entre outros.

A população da pesquisa é composta pelas empresas de capital aberto pertencentes ao setor de consumo não-cíclico do Brasil, Argentina e Chile, sendo analisadas as notas explicativas do período de $2015 \mathrm{e}$ 2016. Desta forma, foram selecionadas, através do programa Thomson 32 empresas do Brasil, 14 empresas da Argentina e 36 do Chile, tendo como população final o total de 82 empresas.

Foi necessário excluir uma empresa argentina e duas chilenas por falta de documentos para análise, totalizando uma amostra final de 79 empresas. As demonstrações contábeis brasileiras foram retiradas através das empresas listadas na B3, as demonstrações argentinas mediante o site Bolsar e, por fim, as demonstrações chilenas, por meio do site Superintendencia Valores Y Seguros (SVS).

Frente a isso se expõe a Figura 1, representando os cinco quesitos que serão analisados na nota explicativa de cada empresa. Os quesitos foram extraídos diretamente do tópico de divulgação do CPC 27 ativo imobilizado.

Figura 1: Quesitos de Divulgação do Pronunciamento Técnico CPC 27

\begin{tabular}{|c|l|}
\hline Item $\mathbf{N}^{\mathbf{0}}$ & \multicolumn{1}{c|}{ Descrição dos Quesitos } \\
\hline 1 & Apresentou os critérios de mensuração utilizados para determinar o valor contábil bruto. \\
\hline 2 & Apresentou os métodos de depreciação utilizados. \\
\hline 3 & Apresentou as vidas úteis ou as taxas de depreciação utilizadas. \\
\hline 4 & Apresentou a conciliação do valor contábil no início e no final do período (demonstrando adições, depreciações, etc). \\
\hline 5 & Divulgou parte da depreciação reconhecida no resultado e parte da depreciação que é custo de outros ativos. \\
\hline
\end{tabular}

Fonte: Elaborada pelos autores, com base no CPC27

Para cada item demonstrado foi estipulado um critério de pontuação, um ponto se a empresa atendeu a exigência e zero se não atendeu, dessa forma, se a entidade adotasse todos os quesitos, obteria o score de cinco pontos representando $100 \%$ de coerência.

0 índice de disclosure utilizado foi o somatório de itens divulgados pela empresa (di) dividido pelo somatório dos itens que deveriam ter sido apresentados (dj).

$$
\mathrm{INDCOMB}=\frac{\sum_{i=1}^{n} d i}{\sum_{j=1}^{m} d j}
$$

Este índice foi utilizado nos estudos de Nakayma (2012), tratando da evidenciação de operações de combinação de negócios. $O$ índice é denominado INDCOMB, e será adaptado para esta pesquisa aplicando-0 nos quesitos descritos na Figura 1. 


\section{Análise dos Resultados}

Nesse tópico será apresentada a análise referente às empresas brasileiras, argentinas e chilenas conforme descrito na metodologia da pesquisa. Utilizando as notas explicativas dos períodos de 2015 e 2016, foi possível elaborar um comparativo entre os países estudados, por meio do nível de disclosure médio de cada quesito exposto sobre a divulgação do ativo imobilizado. A Tabela 1 traz a primeira análise após todos os resultados coletados, evidenciando o INDCOMB por categoria e país:

Tabela 1: Nível médio de disclosure por quesito e país

\begin{tabular}{|c|c|c|c|c|c|c|c|c|c|c|c|c|}
\hline \multirow{3}{*}{ Quesitos } & \multicolumn{6}{|c|}{2015} & \multicolumn{6}{|c|}{2016} \\
\hline & & Brasil & & Argentina & & Chile & & Brasil & & Argentina & & Chile \\
\hline & Qtde. & INDCOMB & Qtde. & INDCOME & Qtde. & INDCOMB & Qtde. & INDCOMB & Qtde. & INDCOM & Qtde. & INDCOMB \\
\hline 1 & 30 & $94 \%$ & 13 & $100 \%$ & 34 & $100 \%$ & 30 & $94 \%$ & 13 & $100 \%$ & 34 & $100 \%$ \\
\hline 2 & 29 & $91 \%$ & 13 & $100 \%$ & 33 & $97 \%$ & 30 & $94 \%$ & 13 & $100 \%$ & 33 & $97 \%$ \\
\hline 3 & 31 & $97 \%$ & 12 & $92 \%$ & 34 & $100 \%$ & 31 & $97 \%$ & 12 & $92 \%$ & 34 & $100 \%$ \\
\hline 4 & 32 & $100 \%$ & 13 & $100 \%$ & 34 & $100 \%$ & 31 & $97 \%$ & 13 & $100 \%$ & 34 & $100 \%$ \\
\hline 5 & 4 & $13 \%$ & 1 & $8 \%$ & 7 & $21 \%$ & 4 & $13 \%$ & 1 & $8 \%$ & 6 & $18 \%$ \\
\hline
\end{tabular}

Fonte: Elaborada pelos autores

É possível observar na Tabela 1 que, para o ano de 2015, o primeiro quesito foi totalmente divulgado pelas empresas da Argentina e do Chile, obtendo desta forma, 100\% de disclosure. Em contrapartida, as empresas brasileiras atingiram o percentual de $94 \%$ quanto à evidenciação do ativo imobilizado, demonstrando inferioridade de $6 \%$ em relação à comparação com os demais países. Já para o quesito dois, obteve-se $100 \%$ de INDCOMB somente para as empresas da Argentina, para fins de comparação, o Brasil demonstrou inferioridade de $9 \%$ e o Chile de $3 \%$.

No terceiro quesito, as empresas chilenas demonstraram vantagem para com os demais, obtendo 0 percentual máximo de divulgação. Frente a isso, o Brasil apresentou desvantagem de $3 \%$, já para as empresas argentinas, o percentual comparativo foi inferior em $8 \%$. Em relação ao quinto quesito, novamente o Chile apresentou superioridade, sendo esta de $8 \%$ sobre o Brasil e de $13 \%$ sobre a Argentina.

No entanto, observa-se que para o quesito quatro, todas as empresas dos três países analisados atenderam a exigência do CPC 27, demonstrando a conciliação do valor contábil no início e no fim do período. Dessa maneira, o INDCOMB atingido foi de 100\%, sendo esse o único quesito homogêneo entre as variáveis analisadas.

O segundo período a ser analisado é o ano de 2016, diante disso, pode-se observar mediante a Tabela 1, que para os quesitos um e três, o resultado atingido se manteve o mesmo que o do período anterior. Já no item 2, as empresas brasileiras diminuíram a diferença para com as argentinas, o percentual inferior que antes era de $9 \%$, passou a ser de $6 \%$.

Nota-se também que no primeiro período, o requisito quatro apresentava INDCOMB de 100\% para todos os países analisados, porém, para 2016, o resultado sofreu alterações negativas, demonstrando que as empresas brasileiras reduziram este percentual em $3 \%$, atingindo assim, nível médio de disclosure de $97 \%$.

Por fim, para o quinto quesito ocorreu situação semelhante à mencionada no parágrafo anterior, relatando que as empresas do Chile reduziram seu percentual de 2015 para 2016 em 3\%, atingindo no último período disclosure de $18 \%$. 
Além disso, há que se atentar para a grande diferença que o último requisito impõe sobre os outros. As exigências do CPC de um a quatro, obtiveram percentuais acima de $90 \%$ nos dois períodos analisados, porém, como se pode observar, o quesito número cinco teve seu percentual máximo de $21 \%$, demonstrando completa desconsideração pelas empresas. Esse resultado se aplica para os três países e para os dois anos analisados, sendo que, em 2016, o percentual máximo sofreu redução, atingindo apenas 18\%. A Tabela 2 ilustra o índice de evidenciação atingido por empresa durante os períodos analisados, conforme segue:

Tabela 2: Índice de evidenciação por empresa

\begin{tabular}{c|ccc|ccc}
\hline \multirow{2}{*}{ INDCOMB } & \multicolumn{3}{|c|}{2015} & \multicolumn{3}{c}{2016} \\
& Brasil & Argentina & Chile & Brasil & Argentina & Chile \\
\hline \hline $100 \%$ & 2 & 1 & 7 & 3 & 1 & 6 \\
$80 \%$ & 27 & 11 & 26 & 25 & 11 & 27 \\
$60 \%$ & 2 & 1 & 1 & 3 & 1 & 1 \\
$40 \%$ & 1 & 0 & 0 & 1 & 0 & 0 \\
\hline
\end{tabular}

Fonte: Elaborada pelos autores

A Tabela 2 proporciona a visualização por empresa em relação à evidenciação dos quesitos propostos para a pesquisa. Considerando o INDCOMB de 100\%, pode-se observar em 2015 que, das empresas brasileiras analisadas, apenas duas atenderam todos os quesitos determinados, quanto às argentinas, somente uma alcançou este percentual, e por fim, o Chile teve o melhor resultado, totalizando sete empresas.

No entanto, é possível verificar que a maioria das companhias apresentou $80 \%$ das exigências, deixando de cumprir um quesito proposto. Em relação ao Brasil, 27 companhias se enquadraram neste resultado, já para a Argentina, foram 11 e quanto ao Chile, observa-se o total de 26 empresas.

Como se observa, o disclosure de $60 \%$ representa poucas empresas, sendo que para este percentual, foram ignorados dois itens referentes à divulgação do ativo imobilizado. Mediante isso, dentre as empresas, duas brasileiras se enquadraram neste índice, uma argentina e uma chilena. Já para o INDCOMB de 40\%, as entidades que auferiram esse resultado, tiveram de ignorar três quesitos propostos pelo CPC 27 , observando a tabela acima, pode-se concluir que apenas o Brasil alcançou esse baixo percentual, representado por uma empresa.

Para o ano de 2016, ocorreram algumas modificações em relação ao período antecessor, primeiramente quanto ao INDCOMB de 100\%. Neste índice, o Brasil somou mais uma empresa, demonstrando eventual melhora na divulgação do ativo imobilizado, totalizando três entidades que divulgaram corretamente suas informações. Porém outra mutação ocorreu, as empresas chilenas demonstraram redução na divulgação das informações, totalizando 6 empresas com o percentual máximo, caracterizando em decrescimento entre os períodos.

O disclosure de $80 \%$ para o ano 2016 permaneceu como o índice que comporta o maior número de empresas. Para esse, o Brasil atingiu o total de 25 organizações, a Argentina 11 e 0 Chile 27, refletindo em diferença quanto ao período anterior. Ainda, de acordo com a tabela 2, pode-se verificar que para o índice de $60 \%$, basicamente não houve modificação, diante disso, uma empresa brasileira acabou integrando o total, obtendo três organizações neste percentual. O último INDCOMB mencionado é de $40 \%$, para este, permaneceram os mesmos resultados atingidos no ano de 2015.

Por meio da análise, é possível realizar a comparação entre os dois períodos estudados, determinando como ocorreram as mutações que influenciaram no total de empresas em cada índice atingido. Nesse sentido, o Brasil teve modificações significativas, das 27 empresas que se encontravam com INDCOMB de $80 \%$ em 2015, uma delas passou a atingir o percentual máximo, e outra, reduziu seu aproveitamento, alcançando 0 índice de $60 \%$. 
Verificou-se, também, que o Chile demonstrou diferença entre os anos, uma de suas empresas que se enquadrava no percentual máximo, passou no último período a integrar o INDCOMB de $80 \%$, evidenciando regressão quanto ao disclosure. Por fim, não foram constatadas diferenças para as empresas argentinas, os resultados foram os mesmos durante os dois períodos. A Tabela 3 retrata quais os quesitos ignorados pelas empresas que atingiram o INDCOMB de $80 \%$, conforme segue:

Tabela 3: Quesitos ignorados para INDCOMB de $80 \%$

\begin{tabular}{cccc|cccc}
\hline \multicolumn{7}{c}{ DISCLOSURE 80\% } \\
\hline $\begin{array}{c}\text { Quesito } \\
\text { Ignorado }\end{array}$ & $\begin{array}{c}\text { Brasil } \\
\text { Qtde. empresas }\end{array}$ & $\begin{array}{c}\text { Argentina } \\
\text { Qtde. empresas }\end{array}$ & $\begin{array}{c}\text { Chile } \\
\text { Qtde. empresas }\end{array}$ & $\begin{array}{c}\text { 2016 } \\
\text { Quesito }\end{array}$ & $\begin{array}{c}\text { Brasil } \\
\text { Ignorado }\end{array}$ & $\begin{array}{c}\text { Argentina } \\
\text { Qtde. empresas }\end{array}$ & $\begin{array}{c}\text { Qtde. empresas } \\
\text { Qtde. empresas }\end{array}$ \\
\hline \hline 1 & 0 & 0 & 0 & 1 & 0 & 0 & 0 \\
2 & 2 & 0 & 0 & 2 & 1 & 0 & 0 \\
3 & 0 & 0 & 0 & 3 & 0 & 0 & 0 \\
4 & 0 & 0 & 0 & 4 & 0 & 0 & 0 \\
5 & 25 & 11 & 26 & 5 & 24 & 11 & 27 \\
\hline \hline Total & 27 & 11 & 26 & Total & 25 & 11 & 27 \\
\hline
\end{tabular}

Fonte: Elaborada pelos autores

Por meio da Tabela 3, é possível visualizar durante os dois períodos analisados, a quantidade de empresas que alcançaram o disclosure de $80 \%$, e que deixaram de evidenciar um quesito proposto. Perante os dados expostos, pode-se definir que, tanto para 2015 quanto para 2016, os três países tiveram resultados idênticos, demonstrando que, no geral, o requisito ignorado foi o de número cinco.

O quesito cinco trata-se da necessidade de demonstrar a parte da depreciação reconhecida no resultado e a parte reconhecida como custo de outros ativos. Para todos os países analisados, a evidenciação deste item foi extremamente baixa, revelando que praticamente todas as empresas estão em desconformidade com esta exigência do CPC 27. É interessante acrescentar, ainda, que este item foi fator determinante para reduzir bruscamente a quantia de entidades com $100 \%$ de coerência quanto ao disclosure.

Para as companhias argentinas e chilenas enquadradas nesse percentual, todas omitiram a informação pertinente ao quesito cinco, somente o Brasil possuiu resultados divergentes aos demais países, sendo que, no ano de 2015, duas empresas deixaram de evidenciar o quesito dois e, em 2016, esse número foi reduzido para uma companhia. A Tabela 4 proporciona a visualização dos quesitos ignorados pelas empresas que atingiram o INDCOMB de 60\%, conforme segue:

Tabela 4: Quesitos ignorados para INDCOMB de $60 \%$.

\begin{tabular}{cccc|cccc}
\hline \multicolumn{1}{c}{ DISCLOSURE $60 \%$} \\
$\begin{array}{c}\text { Quesito } \\
\text { Ignorado }\end{array}$ & $\begin{array}{c}\text { Brasil } \\
\text { Qtde. empresas }\end{array}$ & $\begin{array}{c}\text { Argentina } \\
\text { Qtde. empresas }\end{array}$ & $\begin{array}{c}\text { Chile } \\
\text { Qtde. empresas }\end{array}$ & $\begin{array}{c}\text { 2uesito } \\
\text { Ignorado }\end{array}$ & $\begin{array}{c}\text { Brasil } \\
\text { Qtde. empresas }\end{array}$ & $\begin{array}{c}\text { Argentina } \\
\text { Qtde. empresas }\end{array}$ & $\begin{array}{c}\text { Qtde. empresas } \\
\text { Chile }\end{array}$ \\
\hline \hline 1 & 1 & 0 & 0 & 1 & 1 & 0 & 0 \\
3 & 0 & 0 & 1 & 2 & 0 & 0 & 1 \\
4 & 1 & 1 & 0 & 3 & 1 & 1 & 0 \\
5 & 0 & 0 & 0 & 4 & 1 & 0 & 0 \\
\hline \hline Total & 2 & 1 & 1 & 5 & 3 & 1 & 1 \\
\hline
\end{tabular}

Fonte: Elaborada pelos autores. 
Ao analisar a Tabela 4, deve-se levar em consideração que as empresas pertencentes ao INDCOMB de $60 \%$, deixaram de cumprir com duas exigências de divulgação do ativo imobilizado. $O$ total exposto na tabela demonstra o número de empresas, logo, a somatória dos itens ignorados não irá coincidir com o total demonstrado, pois cada empresa desatendeu duas obrigações.

Diante disso, observando o ano de 2015, verifica-se que o único requisito totalmente atendido pelas empresas enquadradas neste índice, foi o de número quatro. Os demais quesitos foram rejeitados pelas companhias, demonstrando resultados diferentes para cada país. Frente a isso, é necessário destacar que em relação às duas empresas brasileiras, ambas ignoraram o item cinco, e respectivamente uma rejeitou 0 item um e a outra o item três, alcançando o total de dois requisitos ignorados para cada companhia.

Já para 2016, todas as obrigações foram ignoradas, tendo os países sua particularidade quanto à inconformidade. Desta forma, é possível visualizar neste período que, das três empresas brasileiras enquadradas neste percentual, todas ignoraram o item cinco, e respectivamente uma desconsiderou o item um, a outra 0 item três e a última o item número quatro, atingindo o total de dois requisitos ignorados para cada entidade.

Observa-se nitidamente que o item cinco foi rejeitado por todas as empresas pertencentes ao disclosure de $60 \%$, independentemente do país e período analisado. A Tabela 5 evidencia os requisitos ignorados pelas empresas que atingiram o INDCOMB de $40 \%$, conforme segue:

Tabela 5: Quesitos ignorados para INDCOMB de $40 \%$.

\begin{tabular}{cccc|cccc}
\hline \multicolumn{7}{c}{ DISCLOSURE 40\% } \\
\hline $\begin{array}{c}\text { Quesito } \\
\text { Ignorado }\end{array}$ & $\begin{array}{c}\text { Brasil } \\
\text { Qtde. empresas }\end{array}$ & $\begin{array}{c}\text { Argentina } \\
\text { Qtde. empresas }\end{array}$ & $\begin{array}{c}\text { Chile } \\
\text { Qtde. empresas }\end{array}$ & $\begin{array}{c}\text { Quesito } \\
\text { Ignorado }\end{array}$ & $\begin{array}{c}\text { Brasil } \\
\text { Qtde. empresas }\end{array}$ & $\begin{array}{c}\text { Argentina } \\
\text { Qtde. empresas }\end{array}$ & $\begin{array}{c}\text { Qtde. empresas } \\
\text { Chile }\end{array}$ \\
\hline \hline 1 & 1 & 0 & 0 & 1 & 1 & 0 & 0 \\
2 & 1 & 0 & 0 & 2 & 1 & 0 & 0 \\
3 & 0 & 0 & 0 & 3 & 0 & 0 & 0 \\
4 & 0 & 0 & 0 & 4 & 0 & 0 & 0 \\
5 & 1 & 0 & 0 & 5 & 1 & 0 & 0 \\
\hline \hline Total & 1 & 0 & 0 & Total & 1 & 0 & 0 \\
\hline
\end{tabular}

Fonte: Elaborada pelos autores.

Ao visualizar a Tabela 5, deve-se levar em consideração que as empresas pertencentes ao INDCOMB de $40 \%$, deixaram de cumprir com três exigências de divulgação do ativo imobilizado. 0 total exposto na tabela demonstra o número de empresas, logo, a somatória dos itens ignorados não irá coincidir com o total demonstrado, pois cada empresa desatendeu três obrigações.

Durante os dois períodos analisados, apenas uma empresa brasileira obteve esse baixo percentual, expondo poucas informações relativas ao ativo imobilizado em sua nota explicativa. Neste caso, a empresa não divulgou o critério de mensuração utilizado, os métodos de depreciação utilizados, e a segregação da depreciação para custo e despesa, totalizando $60 \%$ de inconformidade.

Em função disso, fica impossibilitado que terceiros interessados visualizem os métodos e procedimentos adotados pela companhia em questão, restringindo o acesso às informações de seus ativos imobilizados. A argentina e o Chile não auferiram o INDCOMB de 40\%. Na Tabela 6, está demonstra o total de quesitos divulgados e ignorados e o percentual de disclosure total por país no período de 2015: 
Tabela 6: Percentual total de disclosure por país em 2015.

\begin{tabular}{|c|c|c|c|c|c|c|c|c|c|}
\hline \multicolumn{10}{|c|}{2015} \\
\hline \multirow{3}{*}{ INDCOMB } & \multirow{3}{*}{ Empresas } & \multirow{2}{*}{\multicolumn{2}{|c|}{$\begin{array}{l}\text { Brasil } \\
\text { Quesitos }\end{array}$}} & \multirow{3}{*}{ Empresas } & \multicolumn{2}{|l|}{ Argentina } & \multicolumn{3}{|c|}{ Chile } \\
\hline & & & & & Ques & itos & & Ques & itos \\
\hline & & Divulgados & Ignorados & & Divulgados & Ignorados & Empresas & Divulgados & Ignorados \\
\hline $100 \%$ & 2 & 10 & 0 & 1 & 5 & 0 & 7 & 35 & 0 \\
\hline $80 \%$ & 27 & 108 & 27 & 11 & 44 & 11 & 26 & 104 & 26 \\
\hline $60 \%$ & 2 & 6 & 4 & 1 & 3 & 2 & 1 & 3 & 2 \\
\hline $40 \%$ & 1 & 2 & 3 & 0 & 0 & 0 & 0 & 0 & 0 \\
\hline Total & 32 & 126 & 34 & 13 & 52 & 13 & 34 & 142 & 28 \\
\hline Percentuais & - & $78,75 \%$ & $21,25 \%$ & - & $80,00 \%$ & $20,00 \%$ & - & $83,53 \%$ & $16,47 \%$ \\
\hline
\end{tabular}

Fonte: Elaborada pelos autores.

A Tabela 6 registra o total de quesitos divulgados e ignorados para cada país analisado no ano de 2015, retratando como informação principal, os percentuais pertinentes aos requisitos. O Brasil é representado por 32 empresas, logo, cada uma delas é responsável em divulgar os cinco quesitos propostos, totalizando, assim, 160 itens a serem evidenciados. Já para as 13 empresas da Argentina o montante de quesitos a serem divulgados seria de 65 e, para as 34 empresas chilenas, é fixado o total de 170 itens obrigatórios.

Conforme os dados apresentados na tabela, as companhias brasileiras atingiram o total de 126 itens divulgados, estabelecendo um percentual de $78,75 \%$. Já para os 34 itens ignorados o percentual foi de $21,25 \%$ desfavorável. As empresas argentinas alcançaram o total de 52 requisitos divulgados, exibindo um percentual de $80 \%$ sobre montante de 65 . Já para os itens ignorados, considera-se $20 \%$ de incoerência.

Por outro lado, o Chile demonstrou o melhor resultado, obtendo 142 quesitos divulgados, desta forma, conquistando $83,53 \%$ sobre os 170 itens obrigatórios. No entanto, quanto aos 28 requisitos ignorados, 0 percentual fixou-se em 16,47\%. Dessa perspectiva, as empresas chilenas foram mais eficientes em demonstrar as informações sobre seus ativos imobilizados nas notas explicativas. A Tabela 7, a última a ser analisada, simboliza o total de quesitos divulgados e ignorados e o percentual de disclosure total por país no período de 2016:

Tabela 7: Percentual total de disclosure por país em 2016.

\begin{tabular}{|c|c|c|c|c|c|c|c|c|c|}
\hline \multicolumn{10}{|c|}{2016} \\
\hline \multirow{3}{*}{ INDCOMB } & \multicolumn{3}{|c|}{ Brasil } & \multicolumn{3}{|c|}{ Argentina } & \multicolumn{3}{|c|}{ Chile } \\
\hline & \multirow{2}{*}{ Empresas } & \multicolumn{2}{|c|}{ Quesitos } & \multirow{2}{*}{ Empresas } & \multicolumn{2}{|c|}{ Quesitos } & \multirow{2}{*}{ Empresas } & \multicolumn{2}{|c|}{ Quesitos } \\
\hline & & Divulgad & Ignorados & & Divulga & Ignorados & & Divulgad & Ignorados \\
\hline $100 \%$ & 3 & 15 & 0 & 1 & 5 & 0 & 6 & 30 & 0 \\
\hline $80 \%$ & 25 & 100 & 25 & 11 & 44 & 11 & 27 & 108 & 27 \\
\hline $60 \%$ & 3 & 9 & 6 & 1 & 3 & 2 & 1 & 3 & 2 \\
\hline $40 \%$ & 1 & 2 & 3 & 0 & 0 & 0 & 0 & 0 & 0 \\
\hline Total & 32 & 126 & 34 & 13 & 52 & 13 & 34 & 141 & 29 \\
\hline Percentuais & - & $78,75 \%$ & $21,25 \%$ & - & $80,00 \%$ & $20,00 \%$ & - & $82,94 \%$ & $17,06 \%$ \\
\hline
\end{tabular}

Fonte: Elaborada pelos autores.

A Tabela 7 registra o total de quesitos divulgados e ignorados para cada país analisado no ano de 2016, retratando como informação principal, os percentuais pertinentes aos requisitos. Essa tabela basicamente é idêntica à Tabela 6 , que demonstra os dados pertinentes ao período de 2015. Desta forma, o número total de quesitos a serem evidenciados por país é o mesmo já mencionado anteriormente. 
Para as empresas brasileiras e argentinas não ocorreram modificações nos percentuais de itens divulgados e ignorados, permanecendo os mesmos que os demonstrados no ano de 2015, logo, a análise é idêntica.

Entretanto, o Chile apresentou decrescimento em seu percentual de itens divulgados. Para o período de 2016, as companhias chinelas obtiveram o total de 141 quesitos evidenciados, alcançando o percentual de $82,94 \%$. Já para os itens ignorados, obteve-se o montante de 29 requisitos, esses representados por 17,06 \%. Contudo, mesmo após a redução de percentual, o Chile ainda mantém melhor resultado quando comparado ao Brasil e à Argentina, fixando superioridade em relação ao disclosure do ativo imobilizado.

\section{Conclusões}

Este estudo objetivou conhecer o nível de disclosure das empresas brasileiras, argentinas e chilenas de capital aberto em relação ao atendimento dos requisitos de divulgação do pronunciamento técnico CPC 27 - Ativo Imobilizado. Através do programa Thomson, foram selecionadas as organizações, totalizando 32 empresas do Brasil, 13 da Argentina e 34 do Chile, todas pertencentes ao setor de consumo não-cíclico, tendo como base para a análise as notas explicativas dos anos de 2015 e 2016, verificando-se 0 atendimento ou não dos requisitos propostos.

Os resultados revelam inicialmente que em nenhum dos três países analisados foi possível obter $100 \%$ de aderência em todos os quesitos aplicados, desta forma, ocorrendo variações conforme quesito, país e período estudado.

Em relação aos quesitos divulgados e ignorados por empresa, foi possível concluir que, no período de 2015, as empresas chilenas demonstraram maior aproveitamento em relação às companhias do Brasil e da Argentina, conquistando o maior percentual de INDCOMB, $83,53 \%$. No período seguinte, o resultado mantevese o mesmo, fixando a superioridade das empresas chilenas quanto à divulgação dos dados inerentes ao ativo imobilizado, porém, o percentual sofreu alterações negativas, desta forma, totalizando $82,94 \%$. As empresas brasileiras apresentaram INDCOMB de 78,75\%, para os anos de 2015 e 2016, já as argentinas auferiram 0 INDCOMB de $80,00 \%$, para os dois períodos analisados.

O quesito com menor índice de evidenciação foi o número 5, que trata da segregação da depreciação, expondo parte desta, que é custo de outros ativos e parte, que é despesa. Para o período de 2015, apenas quatro empresas brasileiras divulgaram essa informação em suas notas explicativas, representando $13 \%$ de disclosure. Em relação às empresas argentinas somente uma divulgou este quesito, representando $8 \%$ de disclosure. Já para o Chile, o montante de sete empresas evidenciou este item, estabelecendo $21 \%$ de INDCOMB.

Contudo, no ano de 2016, basicamente manteve-se o resultado do período anterior, ocorrendo divergência apenas para as empresas chilenas que, neste caso, reduziram o percentual de INDCOMB do quesito 5 para $18 \%$, alcançando o montante de seis empresas que apresentaram conformidade com o quinto quesito. Em todos os países a evidenciação desta informação foi muito inferior ao se comparar com os outros quesitos propostos, demonstrando elevado nível de inconformidade das organizações em expor a segregação do valor depreciável no período analisado.

Das 79 empresas que compõe a amostra para análise, apenas duas brasileiras, uma argentina e sete chilenas auferiram $100 \%$ de disclosure no ano de 2015 , divulgando todos os requisitos propostos em suas demonstrações financeiras. Já para o período de 2016, o resultado sofreu alterações, devido ao Chile reduzir o número de empresas com o percentual máximo, desta vez, totalizando apenas seis empresas, e o Brasil, que somou uma organização ao total apresentado no período anterior. 
O esperado é que todas as companhias obtenham $100 \%$ de atendimento às exigências do CPC 27 , podendo assim demonstrar total transparência em suas demonstrações contábeis para os usuários interessados, porém, os resultados não são satisfatórios.

Recomenda-se que para novas pesquisas, seja efetuada a análise do nível de disclosure das empresas pertencentes a outros setores economicamente representativos, visando realizar a comparação entre o Brasil e outros países. Pode-se também efetuar uma continuação da análise que foi executada neste trabalho, visando verificar outros períodos e incluir mais países para uma nova comparação. A análise de outros períodos possibilita visualizar a evolução da evidenciação durante os anos propostos.

\section{Referências}

Almeida, M. C. (2014). Curso de contabilidade intermediária em IFRS e CPC. São Paulo: Editora Atlas.

Caliman, L. (2015). Disclosure sobre o Ativo Imobilizado: uma análise das Notas Explicativas das empresas do segmento de siderurgia listadas na B3. Revista Brasileira de Contabilidade, (216), 80-89.

CPC, Pronunciamento Técnico $n^{\circ} 27$ (2009). Dispõe sobre o Ativo Imobilizado. Brasília, DF: Comitê de Pronunciamento Contábil.

Eckert, A., Mecca, M. S., Biasio, R., \& de Souza, K. M. (2012). Normas contábeis de reconhecimento e mensuração do ativo imobilizado: impacto em empresas de bens industriais gaúchas listadas na B3. Revista Contabilidade e Controladoria, 4(2).

Gibbins, M., Richardson, A., \& Waterhouse, J. (1990).The management of corporate financial disclosure: opportunism, ritualism, policies and process. Journal of Accounting Research, v. 28, (1), 121-143.

Gil, A. C. (2010). Como elaborar projetos de pesquisa. (5. ed.). São Paulo: Atlas SA.

Gil, A. C. (2008). Métodos e Técnicas de Pesquisa Social. (6. ed.). São Paulo: Atlas SA.

Goulart, A. M. C (2003). Evidenciação Contábil do Risco de Mercado por Instituições Financeiras no Brasil. Dissertação (Mestrado em Ciências Contábeis) da Universidade de São Paulo, SP, Brasil.

ludícibus, S. D., Kanitz, S. C., \& Martins, E. (2010). Contabilidade introdutória. (11. ed.). São Paulo: Atlas SA.

ludícibus, S. D. (2010). Teoria da Contabilidade. (10. ed.). São Paulo: Atlas SA.

Kaveski, I. D. S., da Silva Carpes, A. M., \& Klann, R. C. (2015). Determinantes do Nível de Conformidade das Evidenciações Relativas ao CPC 27 em Empresas do Novo Mercado da B3-DOI: http://dx. doi. org/10.16930/2237-7662/rccc. v14n41p33-45. Revista Catarinense da Ciência Contábil - CRCSC, Florianópolis, 14 (41), 33-45, jan./abr..

Lemos, L. F. B., Longoni, J. M. , \& Lemos, V. O. D. S. (2016). Análise da aplicação do pronunciamento técnico CPC 27 do quesito de divulgação por empresas de capital aberto no setor de comercio. Anais Congresso Brasileiro De Contabilidade, 20, Fortaleza, CE, Brasil, 20

Marion, J. C. (2009). Contabilidade Básica. (10. ed.). São Paulo: Atlas.

Martins, E., Martins, V. A.; \& Martins, É, A. (2007). Normatização Contábil: Ensaio sobre a evolução e o papel do CPC. RIC - Revista de Informação Contábil, Pernambuco, v. 1, (1), 7-30.

Murcia, F. D., SOUZA, F. D., Dill, R. P., \& Costa Junior, N. C. A. (2010). Impacto do nível de disclosure corporativo na volatilidade das ações de companhias abertas no Brasil. Anais do Congresso USP de controladoria e Contabilidade (Vol. 10). Butantã, SP, Brasil.

Oliveira, A. C. L. D., \& Lemes, S. (2012). Análise das demonstrações contábeis brasileiras com a adoção das IFRS/CPC: um estudo comparativo dos indicadores econômico-financeiros para o ano de 2009. Anais do $9^{\circ}$ Congresso USP de Iniciação Cientifica em Contabilidade São Paulo/SP (Vol. 26).

Padoveze, C. L. (2012). Manual de contabilidade básica: contabilidade introdutória e intermediária. (8. ed.). São Paulo: Atlas.

Reis, L. G., \& Nogueira, D. R. (2012). Disclosure do ativo imobilizado: Análise das práticas pelas empresas do novo mercado considerando o CPC 27. Revista de Estudos Contábeis, Londrina, 3(4), 54-67.

Resolução CFC nº 1.055, de 7 de outubro de 2005 (2005). Dispõe sobre a Criação do Comitê de Pronunciamentos Contábeis (CPC), e dá outras providências, Brasília, DF: Comitê de Pronunciamento Contábil. 
Análise do nível de disclosure quanto à aplicação do Pronunciamento Técnico CPC27: um estudo aplicado nas empresas de capital aberto do Brasil, Argentina e Chile.

Silva, M. C., Kutianski, S., \& Scherer, L. M. (2014). Fatores explicativos do nível de evidenciação do ativo imobilizado: um estudo nas empresas do setor industrial listadas na B3. Anais do Congresso XVII Semead - Seminários em Administração, Butantã, SP, Brasil.

Viviani, S., Beck, F., Hall, R. J., \& Klann, R. C. (2014). Evidenciação do ativo imobilizado nas empresas do setor de bens industriais da B3. Enfoque: Reflexão Contábil, Maringá, 33(3), 21-34.

\section{DADOS DOS AUTORES}

\section{Fabrício de Macedo}

Especialista em Gestão Tributária pela INPG

Professor do Curso em Ciências Contábeis do Centro Universitário Católica SC

Endereço: Rua Visconde de Taunay, 427 - Centro

CEP: 89.203-005 - Joinville/SC - Brasil

E-mail: fabricio.macedo@catolicasc.org.br

Telefone: (47) 3145-9700

\section{Lucas Anderson da Silva}

Graduando do Curso de Ciências Contábeis no Centro Universitário Católica de SC

Endereço: Rua Visconde de Taunay, 427 - Centro

CEP: 89.203-005 - Joinville/SC - Brasil

E-mail: lucas1995.silva@catolicasc.org.br

Telefone: (47) 3145-9700

\section{Contribuição dos Autores:}

\begin{tabular}{lcc}
\hline Contribuição & $\begin{array}{c}\text { Fabrício de } \\
\text { Macedo }\end{array}$ & $\begin{array}{c}\text { Lucas da } \\
\text { Silva }\end{array}$ \\
\hline 1. Concepção do assunto e tema da pesquisa & $\sqrt{ }$ & $\sqrt{ }$ \\
2. Definição do problema de pesquisa & $\sqrt{ }$ & $\sqrt{ }$ \\
3. Desenvolvimento das hipóteses e constructos da & $\sqrt{ }$ & \\
pesquisa (trabalhos teórico-empíricos) & & $\sqrt{ }$ \\
4. Desenvolvimento das proposições teóricas & & $\sqrt{ }$ \\
(trabalhos teóricos os ensaios teóricos) & $\sqrt{ }$ \\
5. Desenvolvimento da plataforma teórica & $\sqrt{ }$ & $\sqrt{ }$ \\
6. Delineamento dos procedimentos metodológicos & $\sqrt{ }$ & $\sqrt{ }$ \\
7. Processo de coleta de dados & $\sqrt{ }$ & $\sqrt{ }$ \\
8. Análises estatísticas & $\sqrt{ }$ & $\sqrt{ }$ \\
9. Análises e interpretações dos dados coletados & $\sqrt{ }$ & $\sqrt{ }$ \\
10. Considerações finais ou conclusões da pesquisa & $\sqrt{ }$ \\
11. Revisão crítica do manuscrito & $\sqrt{ }$ & \\
12. Redação do manuscrito & & \\
\hline
\end{tabular}

